\title{
Changes in Myofibrillar and Mitochondrial Compartments during Increased Activity: Dependance from Oxidative Capacity of Muscle
}

\author{
Teet Seene ${ }^{1}{ }^{*}$, Priit Kaasik ${ }^{1}$, Enn Seppet ${ }^{2}$ \\ ${ }^{1}$ Institute of Sport Sciences and Physiotherapy, University of Tartu, Tartu, Estonia \\ ${ }^{2}$ Institute of General and Molecular Pathology, University of Tartu, Tartu, Estonia \\ Email: *teet.seene@ut.ee
}

How to cite this paper: Seene, T., Kaasik, P. and Seppet, E. (2017) Changes in Myofibrillar and Mitochondrial Compartments during Increased Activity: Dependance from Oxidative Capacity of Muscle. Health, 9, 779-798.

https://doi.org/10.4236/health.2017.95056

Received: March 23, 2017

Accepted: May 13, 2017

Published: May 17, 2017

Copyright $\odot 2017$ by authors and Scientific Research Publishing Inc. This work is licensed under the Creative Commons Attribution International License (CC BY 4.0).

http://creativecommons.org/licenses/by/4.0/

\begin{abstract}
Striated muscle tissue contains fibers with high oxidative capacity (heart muscle), higher oxidative capacity (type I and IIA fibers of skeletal muscle) and low oxidative capacity (type IIB/X fibers of skeletal muscle). Muscle fibers with higher oxidative capacity contain large mitochondria tightly packed with cristae as well as small forms of mitochondria containing relatively few cristae. The intensive development of the mitochondrial apparatus in the post-activity period reflects the adaptive processes, which is intended to supply the increased energy requirements of muscle fibers with higher oxidative capacity. Muscle fibers with low oxidative capacity contain significantly less mitochondria than fibers with higher capacity. It is typical to type IIB fibers that after intensive muscle activity there are damaged myofibrils in a relatively small area, some myofibrils are twisted and lose the connection with the neighboring structures. It is still not fully known how skeletal muscles with different oxidative capacity respond to an increased functional activity and what differences exist in these fibers between oxidative capacity and function of myofibrils. The aim of the present short review was to compare structural-functional changes in mitochondrial and myofibrillar compartments of heart and skeletal muscle fibers with different oxidative capacity and the effect of increased functional activity on the interaction of these compartments.
\end{abstract}

\section{Keywords}

Striated Muscle Tissue, Oxidative Capacity, Mitochondrial and Myofibrillar Compartment, Increased Functional Activity

\section{Introduction}

A reciprocal relationship exists between structure and function in contractile 
apparatus of muscle fibers. Structure of myofibrils creates contractile function and the function designs structure. The importance of this relationship changes in situations of different functional demands. Striated muscle tissue contains fibers with high oxidative capacity (heart muscle), higher oxidative capacity (type I and IIA fibers of skeletal muscle) and low oxidative capacity (type IIB/X fibers of skeletal muscle) (Figure 1). According to muscle fibers which have high or higher oxidative capacity, intracellular phosphotransfer systems constitute a major mechanism linking the mitochondria and ATPases within specific structures-intracellular energetic units [1] [2]. Mitochondria are located between the contractile structures in muscle fibers with high oxidative capacity [3]. The efficacy of metabolic signaling significantly depends on morpho-functional relationships of the interaction between mitochondria and sarcomeres [4]. Hypoxia has shown to disturb the connections between mitochondria and sarcomeres as sarcomeric structures disintegrate the muscle fiber structure and cause destruction and cell death [4]. Apoptosis may be one of the reasons of the intensive protein degradation, loss of muscle nuclei associated with atrophy [5]. So, the disruption of desmin damnifies the linking of mitochondria to Z-disc and skeletal muscle demonstrates impaired oxidative phosphorylation [6]. The 5' adenosine monophosphate-activated protein kinase (AMPK) activates in skeletal muscle fibers during acute muscle activity [7]. AMPK is monitoring the energy status of muscle fibers and maintaining muscle fiber energy homeostasis [8].

Long-lasting muscle activity is leading to the depletion of the energy potential, muscular fatigue and destruction of muscle fiber [9]. As children muscle mass is much less in comparison with adults, they generate lower absolute power during intensive muscle activity. Children's muscles are better equipped for oxidative than glycolytic pathways during increased functional activity and have lower capacity to activate type II (fast-twitch) fibers [10]. Oxidative capacity of skeletal muscle increases with aerobic type of muscle activity, and an age-associated decline in oxidative capacity is related to the reduction in fitness [11]. Aerobic type of muscle activity positively influences structural changes to capillarity [12]. Type IIB/IIX muscles exhibit increased ADP concentrations in response to increased workload, which conforms to the respiratory control in skeletal muscles [6]. It is still not fully known how skeletal muscles with different oxidative capacity respond to an increased functional activity and what differences exist in

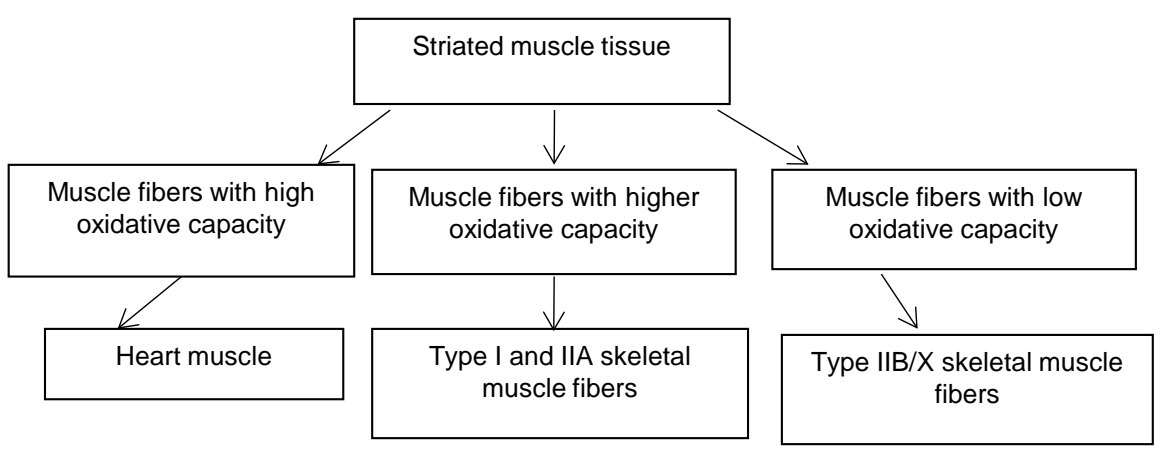

Figure 1. Fiber types of striated muscle tissue according to oxidative capacity. 
these fibers between oxidative capacity and function of myofibrils. The aim of the present short review was to compare structural-functional changes in mitochondrial and myofibrillar compartments of heart and skeletal muscle fibers with different oxidative capacity and the effect of increased functional activity on the co-operation of these compartments.

\section{Effect of Increased Functional Activity on the Muscle Fibers with Higher Oxidative Capacity}

Skeletal muscle is composed of fiber types that have different metabolism, fatigability and contractile properties. Skeletal muscle ability to optimize the response to increased functional activity is based on recruitment of different fiber types. During low intensity and long-lasting activity slow-twitch (ST) and fast-twitch (FT) type IIA muscle fibers are mainly recruited. These fibers have higher oxidative capacity and ST fibers are fatigue resistant. Muscle fibers with higher oxidative capacity (Figure 2) contain large mitochondria tightly packed with cristae as well as small forms of mitochondria containing relatively few cristae [13]. The development of the mitochondrial apparatus after activity period reflects the adaptation of muscle tissue in the conditions of increased energy requirements, particularly of muscle fibers with higher oxidative capacity [14]. The peripheral sarcoplasm of type I and type IIA muscle fibers contain short canals of the granular sarcoplasmic reticulum (SR), polyribosomes and several Golgi complexes close to nucleus. In the recovery period after muscle activity destructive changes ocurred in myofibrils of type I and type IIA muscle fibers. Damages of thick and thin filaments and the disturbance of the regularity of the Z-line in sarcomeres are typical examples of that [15]. Destruction of myofibrils is characteristic of muscle fibers with relatively high oxidative potential. More intensive destruction of myofibrils is appeared in ST type I muscle fibers. In the A-disc of type I fibers some myosin filaments are absent and the destruction of these myofilaments may cover the whole sarcomere. During muscle activity, actin filaments are less damaged than myosin filaments [13]. These structural changes during muscle activity are in accordance with biochemical ones [15] [16] [17]. Relatively small structural rearrangements take place in type IIX/IIB muscle fibers during low intensity muscle activity as these fibers are recruited less. The focal destruction of myofibrils is characteristic change in IIX/IIB fibers. The amount of mitochondria in IIX/IIB fibers did not change significantly during recovery period after increased functional activity. Mitochondria in FT IIB fibers are placed in small groups close to nuclei and between myofibrils on the

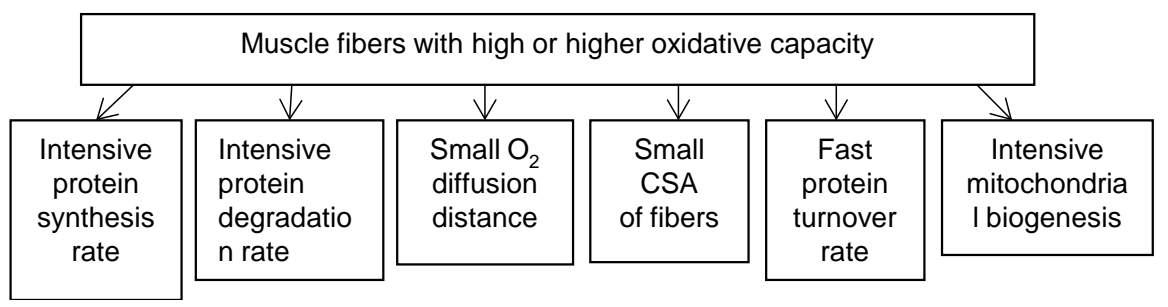

Figure 2. Characterization of muscle fibers with high and higher oxidative capacity. 
level of the Z-line but not in each sarcomere [13].

Type I and IIA muscle fibers have higher plasticity and this is the ground of structural-functional modifications and adaptation of these fiber types to low intensity long-asting functional activity. In the process of adaptation of skeletal muscle to long-asting functional activity (delaying fatigue), the muscle fibers with higher oxidative capacity are playing the central role.

\section{Effect of Increased Functional Activity on the Muscle Fibers with Low Oxidative Capacity}

Muscle fibers with low oxidative capacity (Figure 3 ) contain 2 - 3 times less mitochondria and have structurally and functionally well developed SR and T-system in comparison with fibers which have higher oxidative capacity. These fibers are quickly switched from relaxation to contraction and back to relaxation. Type IIB/X fibers are fast fatigable. The difference in contraction velocity between ST and FT fibers is regulated by the SR, troponin-tropomyosin specific isoforms and myosin heavy chain (MyHC) isoforms. These fibers have best capacity to increase force, explosive power and muscle mass. During the process of adaptation to the intensive functional activity it is typical to type IIB/X fibers that there are damaged myofibrils in a relatively small area, some myofibrils are twisted and lost the connection with the neighboring structures [13].

The morphological adaptations to short-lasting intensive muscle activity involve an increase in the cross-sectional area (CSA) of the whole muscle and individual muscle fibers, and an increase in myofibrils size and number (Figure 4). The hypertrophy response is related to the activation of satellite cells in the early stages of muscle activity [18]. These quiescent myogenic cells are activated after muscle damage. During intensive short-lasting muscle activity morphological adaptations, such as hyperplasia, changes in muscle fine architecture, myofilament density and the structure of connective tissue has been described [18]. Changes induced by intensive muscle activity (increased workload) at the muscle-fiber level are related to hypertrophy of IIA and IIB/X fibers. Increase in the CSA of these fiber types are characteristic for intensive muscular activity but in some studies IIX fibers CSA have been shown to decrease [19]. Activity caused skeletal muscle destruction often follows unaccustomed and sustained metabolically demanding activities [20]. The damages in muscle tissue on the fiber level is caused by excessive strain in the contracting muscle fiber, but not by the absolute force developed in the fiber or the muscle [21].

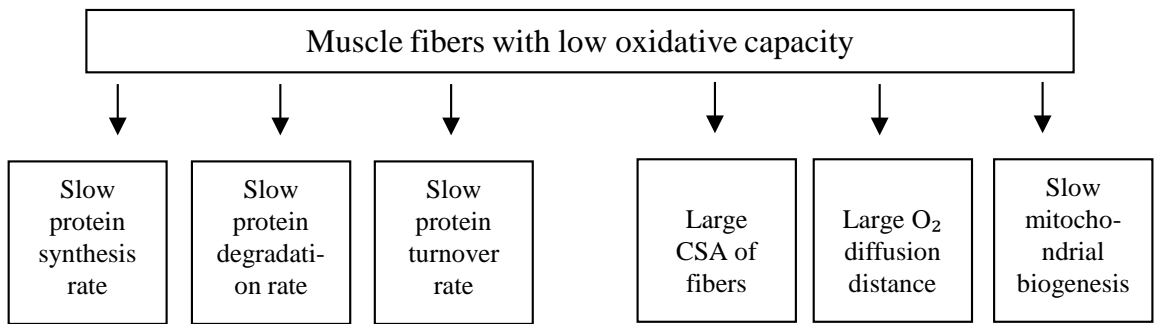

Figure 3. Characterization of muscle fibers with low oxidative capacity. 


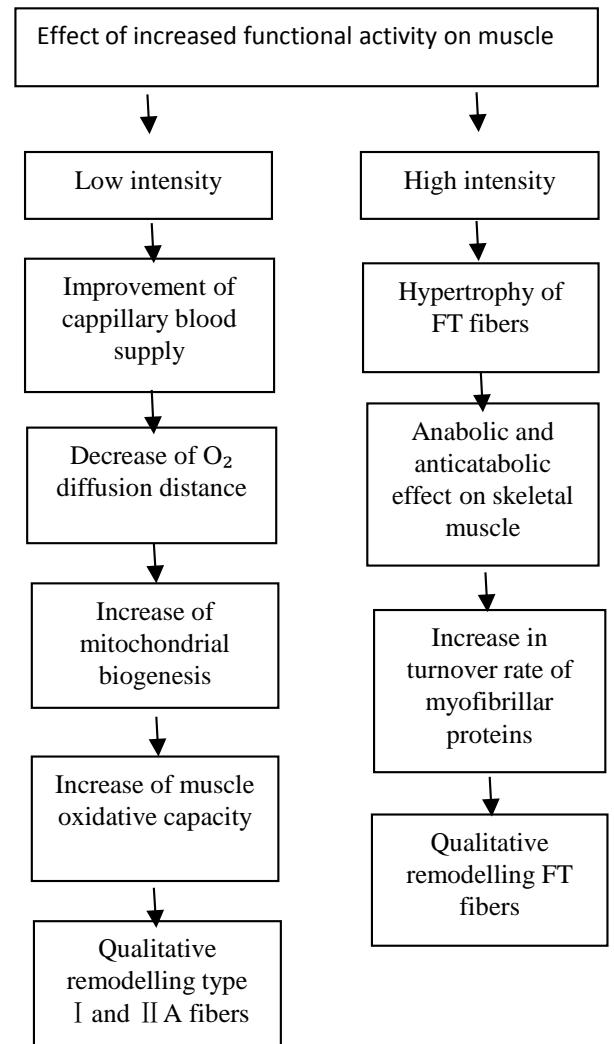

Figure 4. Effect of muscular activity on mitochondrial and myofibrillar compartments.

Anatomically the site of myofibrils injury is the attachment of the myofibrils to the extra sarcolemic cytoskeleton [22]. Adaptational changes in muscle appeared in response to dose of activity and various degrees of adaptation have been mentioned [15]. Muscles adapted to muscular activity show increased neuromuscular excitability, unadapted-reduced neuromuscular excitability. Impaired signal transmission is a reason of peripheral fatigue [23].

Structural changes in skeletal muscle during muscle activity with different duration and intensity are fiber specific (Figure 5 and Figure 6). FT fibers are more vulnerable to muscle activity caused damage than ST fibers [24]. The focal denervation of some muscle fibers during muscle activity is reversible and accompanied by the regeneration of new axonal terminals growing into pre-existing synaptic grooves [13]. Muscle activity may induce complete and focal destruction of some fibers, partial denervation of fibers, and these may be the factors for the activation of satellite cells [25] [26].

\section{Effect of Increased Functional Activity on the Neuromuscular Junctions}

The neuromuscular apparatus, which controls phasic motor impulses as well as neurotrophic influences, provides the plastic activity of the muscle tissue. Increased muscular activity affects the structure of mammalian neuromuscular junctions with changes depending on age, type of muscle fiber and the character 


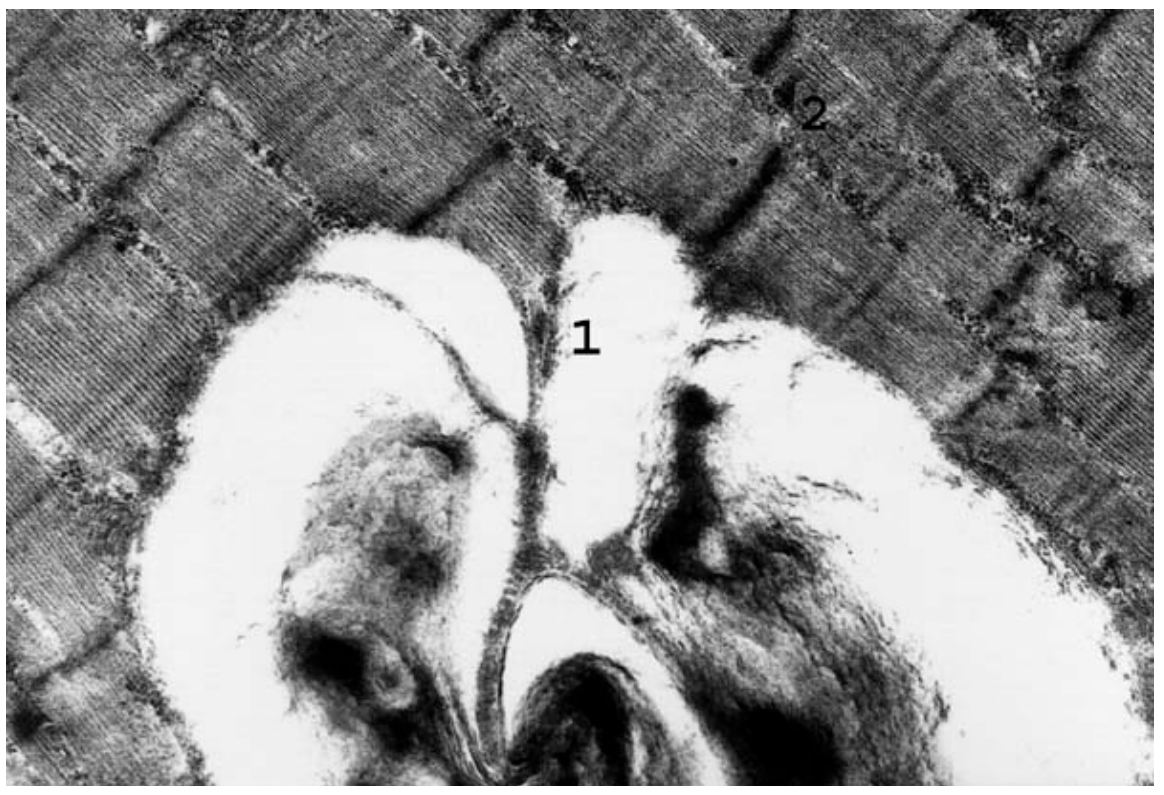

Figure 5. Effect of intensive functional activity on structure of glycolytic muscle fiber (1: focal destruction of myofibrils, some myofibrils have twisted and lost their integrity; 2: thickening of some Z-lines; Magnification 20,750x).

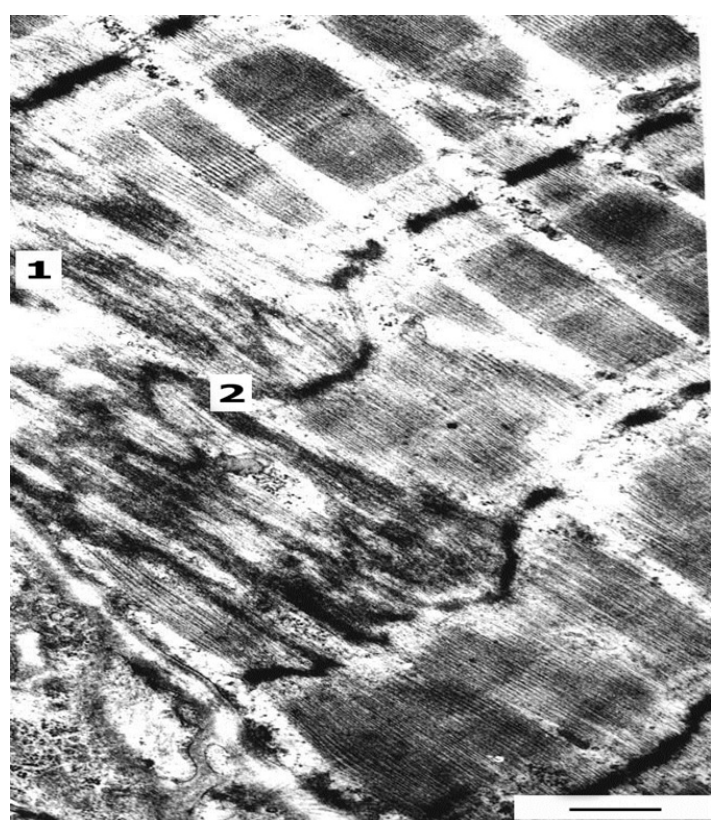

Figure 6. Effect of low intensity functional activity on structure of oxidative muscle fiber (1: destruction of sarcomeres; 2: Z-line has lost its regularity; Magnification 21,750x).

of increased muscular activity [13]. After one week of low intensity muscle activity, a lot of neuromuscular terminals are branching [13]. This type of activity causes the heterogeneity of the structures of the neuromuscular synapses, which is clearly expressed in muscle fibers with higher oxidative capacity. The synapses of type IIA muscle fibers cover a large postsynaptic area as the well-developed synaptic apparatus provides intensive renewal of the structures of the muscle fiber [26]. 
The axon terminals of ST type I muscle fibers have relatively small area, they are round or oval shaped and closely located. The surface of the neighboring neuromuscular contacts is smooth. There is lot of mitochondria in the sarcoplasm near the terminals of the muscle fiber. These mitochondria contain a lot of cristae [13]. The axon terminals of fibers with low oxidative capacity are elliptical and their synaptic vesicles are more generously provided with acetylcholine and other trophic factors. The postsynaptic folds of the neighboring synapses have linked with each other. In comparison with muscle fibers with higher oxidative capacity (type IIA), the postsynaptic folds of type IIB fibers are longer and more regular and they cover a much larger area [13]. In type IIB fibers, the contact area is the largest between the nerve ending and the surface of the muscle fiber.

In muscle fibers with low oxidative capacity, the postsynaptic folds extend near contractile apparatus and are separated from these structures by a thin layer of sarcoplasm. Lot of glycogen granules, some mitochondria and rarely any lysosomes in the terminals and in the postsynaptic area are characteristic of these synapses [13]. Coated vesicles in the sarcoplasm of the postsynaptic area of muscle fibers with higher oxidative capacity are related to the resynthesis of acetylcholine in nerve endings, and they carry the proteins of choline receptors onto the postsynaptic membrane [13]. The connection with the rough sarcoplasmic reticulum may change the regulation of protein metabolism in these fibers [27]. As subsynaptic folds open into T-tubules, they participate in the formation of intermyofibrillar triads [28]. T-tubules in the sole plate greate the network, and together with the sarcoplasmic reticulum form triads. The position of these triads makes them unusable for triggering muscle contraction [29].

\section{Effect of Increased Functional Activity on the Muscle Fiber Oxidative Capacity and Contractile Function}

Skeletal muscle fibers with higher oxidative capacity are relatively small compared to fibers with low oxidative capacity (Figure 2 and Figure 3), pointing to an increase in relationships between fiber CSA and $\mathrm{VO}_{2} \mathrm{max}$ [30]. It is significant that only cardiocytes have high oxidative capacity among striated muscle cells, while skeletal muscle fibers have low (type IIB/X) and higher oxidative capacity (type I and IIA) [2] [4] [13] [14].

$\mathrm{VO}_{2} \mathrm{max}$ is proportional to succinate dehydrogenase (SDH) activity [31], oxoglutarate dehydrogenase activity [32], and to the number of mitochondria [33] [34]. Skeletal muscle fibers with a large CSA had low SDH activity and vice versa [35] [36]. Muscle fibers with higher oxidative capacity contain higher quantities of satellite cells, myonuclei, mitochondria, mRNA, and total ribosomal RNA content. Insulin-like growth factor 1 (IGF-1) is the stimulator of myofibrillar protein synthesis and inhibitor of protein degradation. IGF-1 expression is higher in ST type I muscle fibers [37] [38]. Myostatin is the expression inhibitor of muscle size and proliferation of satellite cells. Expression of myostatin is higher in FT type II fibers [30] [39] [40]. The components of the degradation process of skeletal muscle proteins as ubiquitin ligases MAFbx and MuRF, are 
about twofold higher in fibers with higher in type I and IIA fibers [30]. The higher degradation rate of protein in type I and IIA muscle fibers is balanced by a high rate of protein synthesis. The higher protein synthesis rate may be an important factor limiting the size of type I fibers [30]. Protein turnover rate is faster in type I and IIA muscle fibers. In type I and IIA fibers, the half-life of mitochondrial proteins is the shortest although the turnover of cytochrome $\mathrm{C}$ is higher in type IIX/B fibers [41]. Low intensity muscle activity (Figure 4) stimulates mitochondrial biogenesis and improves its functional parameters [42] [43], improve the energetic potential of skeletal muscle and result in the effective functioning of the muscle contractile apparatus for longer periods of time [12] [44] [45]. Intensity of muscular activity elicits improvements in skeletal muscle both during short-lasting intense and prolonged muscular activity [46]. High intensity muscular activity maintains an endurance potential, muscle oxidative capacity and increases intense level of performance [47] [48]. AMPK is activated in response to muscle activity [49] and related to the regulation of metabolic adaptation of skeletal muscle fibers. AMPK function is regulation of glucose transport, glycogen metabolism, fatty acid oxidation and transcriptional regulation of structural muscle genes [50]. The $\alpha 1$ isoform of AMPK is the regulator of skeletal muscle growth, the $\alpha 2$ isoform regulates metabolic adaptation [51]. The peroxisome proliferator-activated receptor isoform $\delta$ (PPAR $\delta$ ) is the regulator of skeletal muscle endurance capacity. The Ppar $\delta$ gene increases skeletal muscle oxidative capacity as this isoform is by increasing type I fibers and by decreasing type IIX/A fibers, changing the proportion of ST/FT fibers [52] [53].

Increased muscular activity is changes protein turnover. Muscle protein degradation and synthesis rate in the recovery period after activity is increasing [54]. Protein turnover is a rapid way for the redistribution of amino acids into newly synthesized proteins. Amino acids are required because they are derived from protein breakdown and incorporated into newly synthesized protein. Proteins in skeletal muscle turned over slowly, particularly contractile proteins. The turnover rate of $\mathrm{MyHC}$ and MyLC isoforms provides a mechanism, by which the type and amount of protein can be changed in accordance with the needs of the contractile apparatus during the process of adaptation to muscle activity [55] [56]. Activity patterns of muscle fibers where MyHC I and IIa isoforms are dominant, have relatively high oxidative capacity and are recruited during low intensity of activity [16]. It is unclear how much of gene expression of MyHC isoforms is due to genetic predisposition and how much to the specificity of muscle activity [57]. MyHC isoforms' turnover rate between FT muscles depends on the oxidative capacity of fibers [14]. Changes in MyHC isoforms' turnover rate in FT muscles during low intensity muscle activity characterize changes in the contractile machinary through protein metabolism. The character of changes in myosin isoforms' turnover rate shows the significance of $\mathrm{MyHC}$ isoforms in the process of adaptation to muscle activity. C-protein together with MyHC isoforms plays the key role in FT muscle fibers during muscle activity. It is unclear what the role of MyLC isoforms is in FT muscle fibers during muscle activity, 
but changes in MyLC isoforms' relative content and their relation with the character of muscle activity show that MyLC plays a significant role in the process of modulation of the contractile apparatus during muscle activity [54]. Whether other myofibrillar proteins are able to modulate the functional properties of the main contractile protein myosin during muscle activity and if it is depend on the character of increased muscle activity, is still unsolved. C-protein, which binds either myosin or actin, affects the mechanical properties of myosin crossbridges by linking the S2 segment of myosin to the backbone of the thick filament [58]. C-protein is sensitive to the volume (duration) of muscular activity and may cause changes in functional properties of the contractile machinery, particularly during an excessive increase of the volume of muscle activity [17].

\section{Effect of Increased Functional Activity on Muscle Energetics}

In contrast to cardiac muscle, hypertrophy of skeletal muscle is not developed during low intensity functional activity. Skeletal muscles respond to increased functional activity by increasing the fiber composition towards increased proportion of oxidative fibres at the expense of proportion of glycolytic fibres [59]. This change do not give rise to overall muscle size as oxidative fibres CSA is less than glycolytic ones [30]. The proteasome-, lysosome- and $\mathrm{Ca}^{2+}$-mediated protein degradation occurs at higher ratesin oxidative than glycolytic fibres [60]. The mechanisms stimulating either increase of oxidative capacity or fiber hypertrophy seem to exclude each other [30]. Increased mitochondrial biogenesis via AMPK may accompanied by suppression of the myofibrillar protein synthesis through pathways mediated by MAPK and nuclear factor kappa B [30]. Further support for that assumption comes from the finding that increased functional activity, though increasing oxidative metabolism, yet suppresses myofibre growth in myostatin knock-out mice [61]. These facts imply that cardiac and skeletal muscles possess distinct mechanisms for regulation of the balance between the capacities of oxidative potential and hypertrophy in response to low intensity functional activity. These muscle type specific differences in adaptation to increased functional activity can be revealed also at the level of ATP consumption. In cardiac muscle low intensity functional activity results in enhanced myosin ATPase activity along with increased contractility [62]. This change based on the myosin isoenzyme shift towards increased fast V1 $(\alpha)$ isoform [63] and alterations in regulation of myosin ATPase. Low intensity functional activity results in increased myofilament sensitivity to $\mathrm{Ca}^{2+}$ [64], and probably due to augmented expression of atrial MyLC-1 isoform [65] that increases the capacity to consume ATP by myofibrils. This type of increased functional activity also promotes the expression of SR $\mathrm{Ca}^{2+} \mathrm{ATPase}$ (SERCA2) together with increased $\mathrm{Ca}^{2+}$ transport into SR [66]. In addition, $\mathrm{Ca}^{2+}$ removal through trans sarcolemmal route is facilitated due to activation of $\mathrm{Ca}^{2+}$-ATPase localized in sarcolemma [62]. Low intensity functional activity increases the capacity of ATP consumption in cardiac cells, but not in skeletal muscles. 
Skeletal muscle respond to increased functional activity by shifting the myofibre profile towards increased proportion of oxidative fibres characterized with markedly lower ATPase activity [67]. This change is beneficial as it increases the economy of ATP utilization for cross-bridge cycling [57]. Low intensity functional activity stimulates also the $\mathrm{Na}^{+}-\mathrm{K}^{+}$-ATPase activity in skeletal muscle but not in cardiac muscle [62]. Low intensity functional activity stimulates mitochondrial biogenesis and improves the functional capacity of mitochondria in producing ATP in skeletal muscles [43]. Upregulated mitochondrial biogenesis manifests as increases in mitochondrial content per gram of tissue [68], mitochondrial volume relative to fibre area and tissue activity of mitochondrial enzymes [69]. These changes occur simultaneously in oxidative and glycolytic muscle fibres [68]. Increased mitochondrial contribution to energy metabolism is associated with transition from carbohydrate utilization to fat utilization and this is the reason of improvement of the endurance capacity [70].

Low intensity functional activity has shown decreased the oxidation rate of palmitoylcarnitine/malate without changes in pyruvate, 2-oxoglutarate and succinate oxidation [71]. The controversies regard also to morphometric studies. For example increased mitochondria-to-myofibril ratio [72] or no change in this parameter [73]. Increased functional activity though resulting in hypertrophy and increased oxidative capacity of heart, did not increase the volume density of mitochondria [74], mitochondrial volume, despite increased weight and size of the heart [75]. The nature of conflicting data on mitochondrial biogenesis are not clear. Many reasons like intensity and volume of muscular activity, time for recovery between periods of increased functional activities, gender and age differences lead to contraversial results [76]. Activity induced changes in oxidative capacity and size of the striated muscle fibres tend to mutually exclude each other through altered balance between the biosynthesis of contractile proteins and mitochondria [30]. It is clear that the mechanisms of mitochondrial biogenesis differ from those that underlie muscle hypertrophy. Myocytes follow specific and powerful mechanisms capable to preferentially promote the biosynthesis of mitochondria in response to increased workload. Most of these mechanisms converge at peroxisome proliferator-activated receptor gamma coacivator-1alpha (PGC-1 $\alpha$ ), a regulator of oxidative metabolism and mitochondrial content in muscle cells. PGC- $1 \alpha$ binds to DNA-binding transcription factors, such as the nuclear respiratory factors NRF-1 and NFR-2, and trans-activates genes involved in the control over electron transport chain, mitochondrial protein import, and transcription factors Tfam, TFB1M, and TFB2M [77]. Increase in functional activity increases the activity and expression of PGC- $1 \alpha$ in muscle cells through multiple mechanisms. Glucocorticoids activate PGC-1 $\alpha$ through genomic and non-genomic effects [78]. Increased functional activity activates the p38 MAPK [79] which phosphorylates the PGC-1 $\alpha$ repressor protein p160 MBP that relieves the inhibitory effect of repressor on PGC- $1 \alpha$, thereby permitting PGC- $1 \alpha$ to interact with target proteins [80]. p38 MAPK also increases the transcriptional activity of PGC-1 $\alpha$ 
through phosphorylation [81]. AMP produced in exercising muscle cells stimulates AMPK that in turn upregulates the expression of PGC-1 $\alpha$ [82]. PGC- $1 \alpha$ activated by reversible deacetylation carried out by class III histone deacylase SIRT1 [83]. SIRT1 upregulates the expression of PGC- $1 \alpha$ through formation of the SIRT1-MyoD-PGC-1 $\alpha$ complex on PGC-1 $\alpha$ promoter [84]. During incease in functional activity upregulation of SIRT1 occurs rapidly, as its mRNA level increases together with mRNAs for PGC- $1 \alpha$, cytochrome $\mathrm{c}$, and citrate synthase in muscle tissue after intensive cycling [85]. A relevant mechanism appears to be mediated by stimulation of AMPK, as SIRT2 activates the liver kinase B1, a serine-threonine kinase that impels AMPK [86]. In heart and skeletal muscle SIRT3 is localized exclusively within mitochondria and the muscle SIRT3 protein content increases in parallel to elevations in citrate synthase activity and PGC- $1 \alpha$ content among distinct muscle types [87]. Electrical stimulation resulted in increases in SIRT3 protein and PGC-1 $\alpha$ proteins in an AMPKindependent manner [87]. SIRT3 activates also mitochondrial enzymes, such as succinate dehydrogenase, isocitrate dehydrogenase, glutamate dehydrogenase, NDUFA9 subunit of complex I of the respiratory chain, and acetyl-coenzyme A synthase, the targeted activation of SIRT3 may provide a means for shifting metabolism towards use of fatty acids thereby protecting failing heart [86]).

Low intensity functional activity stimulates PGC- $1 \alpha$ through activation of cyclic-nucleotide regulatory binding protein (CREB), in association with upregulation of mitochondrial proteins in heart and skeletal muscle [88]. The CREB-mediated mechanism is specifically targeted by catecholamines. It has been shown that $\mathrm{p} 53$, a tumour suppressor protein, involve in mitochondrial biogenesis. p53 increases the expression of synthesis of cytochrome c oxidase 2 $\left(\mathrm{SCO}_{2}\right)$, an important protein for assambling the cytochrome coxidase complex what is controlling the rate of mitochondrial respiration [89]. p53 translocate into mitochondria for interaction with and activation of the mitochondrial DNA polymerase $\gamma$ [90]. p53 also interacts with Tfam [91]. The importance of p53 in regulation of mitochondrial biogenesis was confirmed in studies on p53 ablated mice [92]. As lack of p53 did not limit the ability of mice to adapt to physical activity by stimulation of mitochondrial biogenesis, factors other than p53 could inducece mitochondrial biogenesis [92]. Every other day feeding of mice in combination with endurance exercise induce changes in cell metabolism, reduce the level of lipid peroxidation in skeletal muscle, improve muscle performance by increasing lipid catabolism in mitochondria and decrease muscle damage during exhaustive exercise [93]. Increased functional activity decreases oxigen diffusion distance in muscle tissue [13] which mean improvement of capillary blood supply. Increased activity stimulates mitochondrial biogenesis, increases oxidative capacity in muscle tissue [14] and turnover rate [56] of sarcoplasmic proteins.

\section{Conclusions}

Striated muscle tissue contains fibers with high oxidative capacity (heart mus- 
cle), higher oxidative capacity (type I and IIA fibers of skeletal muscle) and low oxidative capacity (type IIB/X fibers of skeletal muscle). In muscle fibers with high or higher oxidative capacity intracellular phosphotransfer system constitutes a major mechanism linking the mitochondria and ATPases. In these fibers mitochondria are precisely positioned between the myofilaments, muscle fibers are small compared to fibers with low oxidative capacity and show the relationships between fiber CSA and $\mathrm{VO}_{2} \max$. $\mathrm{VO}_{2}$ max is proportional to $\mathrm{SDH}$ activity or oxoglutarate dehydrogenase activity and consequently to the number of mitochondria. Muscle fibers with a large CSA had low SDH activity. Fibers with higher oxidative capacity contain higher quantities of satellite cells, myonuclei, mitochondria, mRNA, and total ribosomal RNA content. IGF-1 expression, a stimulator of myofibrillar protein synthesis, is also higher in type I fibers. Myostatin, the expression inhibitor of muscle hypertrophy, is higher in type II fibers and the components of the degradation process of skeletal muscle proteins, as ubiquitin ligases MAFbx and MuRF, are about twofold higher in type I and IIA fibers. The rate of protein degradation in type I and IIA muscle fibers is balanced by a high rate of protein synthesis and this may be the limiting factor of the size of fibers. Protein turnover rate is faster in type I and IIA muscle fibers. In type I and IIA fibers the half-life of mitochondrial proteins is the shortest. Low intensity aerobic muscle activity stimulates mitochondrial biogenesis, improves its functional parameters and the energetic potential of skeletal muscle and results in the effective functioning of the muscle contractile apparatus for longer periods of time. Increased muscular activity causes faster protein turnover rate by increasing muscle protein degradation and synthesis rate during the recovery period after muscle activity. Protein turnover is the important step for the redistribution of amino acids as they are derived during protein breakdown and incorporated into the newly synthesized protein. Protein turnover rate in skeletal muscle is slow, particularly contractile proteins. The turnover rate of myosin heavy chain and myosin light chain isoforms is the mechanism, by which the type and amount of protein change in accordance with the needs of the myofibrillar apparatus during adaptation to increased functional activity.

Increased mitochondrial biogenesis via AMPK may be accompanied by suppression of the myofibrillar protein synthesis through pathways mediated by MAPK and nuclear factor kappa B. Further support for that assumption comes from the finding that increased functional activity, though increasing oxidative metabolism, yet suppresses myofibre growth. These facts imply that cardiac and skeletal muscles possess distinct mechanisms for regulation of the balance between the capacities of oxidative potential and hypertrophy in response to low intensity functional activity. Muscle type specific differences in adaptation to increased functional activity revealed also at the level of ATP consumption. In cardiac muscle low intensity functional activity results in enhanced myosin ATPase activity along with increased contractility. This change based on the myosin isoenzyme shifts towards increased fast $\mathrm{V} 1(\alpha)$ isoform and alterations in regulation of myosin ATPase. Low intensity functional activity results in 
increased myofilament sensitivity to $\mathrm{Ca}^{2+}$ and probably due to augmented expression of atrial myosin light chain-1 isoform that increases the capacity to consume ATP by myofibrils. This type of increased functional activity also promotes the expression of SR $\mathrm{Ca}^{2+} \mathrm{ATPase}$ together with increased $\mathrm{Ca}^{2+}$ transport into SR. In addition, $\mathrm{Ca}^{2+}$ removal through trans-sarcolemmal route is facilitated due to activation of $\mathrm{Ca}^{2+}$-ATPase localized in sarcolemma. Low intensity functional activity increases the capacity of ATP consumption in cardiac cells, but not in skeletal muscles. Skeletal muscle responds to increased functional activity by shifting the myofibre profile towards increased proportion of oxidative fibres characterized with markedly lower ATPase activity. This change is beneficial as it increases the economy of ATP utilization for cross-bridge cycling. Low intensity functional activity also stimulates the $\mathrm{Na}^{+}-\mathrm{K}^{+}$-ATPase activity in skeletal muscle but not in cardiac muscle. Low intensity functional activity stimulates mitochondrial biogenesis and improves the functional capacity of mitochondria in producing ATP in skeletal muscles.

\section{Acknowledgements}

This study was supported by the funds of the Ministry of Education and Research of the Republic of Estonia, research project number TKKSB 1787. We would like to thank Piret Pärsim for technical expertise.

\section{References}

[1] Seppet, E.K., Käämbre, T., Sikk, P., Tiivel, T., Vija, H., Tonkonogi, M., Sahlin, K., Kay, L., Appaix, F., Braun, U., Eimre, M. and Saks, V.A. (2001) Functional Complexes of Mitochondria with $\mathrm{Ca}$, MgATPases of Myofibrils and Sarcoplasmic Reticulum in Muscle Cells. Biochimica et Biophysica Acta, 1504, 379-395.

[2] Saks, V.A., Kuznetsov, A.V., Vendelin, M., Guerrero, K., Kay, L. and Seppet, E.K. (2004) Functional Coupling as a Basic Mechansim of Feedback Regulation of Cardiac Energy Metabolism. Molecular and Cellular Biochemistry, 256, 185-199. https://doi.org/10.1023/B:MCBI.0000009868.92189.fb

[3] Vendelin, M., Béraud, N., Guerrero, K., Andrienko, T., Kuznetsov, A.V., Olivares, J., Kay, L. and Saks, V.A. (2005) Mitochondrial Regular Arrangement in Muscle Cells: A "Crystal-Like" Pattern. American Journal of Physiology. Cell Physiology, 288, C757-C767. https://doi.org/10.1152/ajpcell.00281.2004

[4] Seppet, E.K., Eimre, M., Anmann, T., Seppet, E., Peet, N., Käämbre, T., Paju, K., Piirsoo, A., Kuznetsov, A.V., Vendelin, M., Gellerich, F.N., Zierz, S. and Saks, V.A. (2005) Intracellular Energetic Units in Healthy and Diseased Hearts. Experimental and Clinical Cardiology, 10, 173-183.

[5] Dirks, A.J. and Leeuwenburgh, C. (2005) The Role of Apoptosis in Age-Related Skeletal Muscle Atrophy. Sports Medicine, 35, 473-483.

https://doi.org/10.2165/00007256-200535060-00002

[6] Saks, V., Kaambre, T., Sikk, P., Eimre, M., Orlova, E., Paju, K., Piirsoo, A., Appaix, F., Kay, L., Regitz-Zagrosek, V., Fleck, E. and Seppet, E. (2001) Intracellular Energetics Units in Red Muscle Cells. Biochemical Journal, 356, 643-657. https://doi.org/10.1042/bj3560643

[7] Aschenbach, W.G., Sakamoto, K. and Goodyear, L.J. (2004) 5'Adenosine Monophosphate-Activated Protein Kinase, Metabolism and Exercise. Sports Medicine, 34, 
91-103. https://doi.org/10.2165/00007256-200434020-00003

[8] Nader, G.A. (2006) Concurrent Strength and Endurance Training: From Molecules to Man. Medicine and Science in Sports and Exercise, 38, 1965-1970. https://doi.org/10.1249/01.mss.0000233795.39282.33

[9] Abbiss, C.R. and Laursen, P.B. (2005) Models to Explain Fatigue during Prolonged Endurance Cycling. Sports Medicine, 35, 865-898. https://doi.org/10.2165/00007256-200535100-00004

[10] Ratel, S., Duché, P. and Williams, C.A. (2006) Muscle Fatigue during High-Intensity Exercise in Children. Sports Medicine, 36, 1031-1065. https://doi.org/10.2165/00007256-200636120-00004

[11] Russ, D.W. and Kent-Braun, J.A. (2004) Is Skeletal Muscle Oxidative Capacity Decreased in Old Age? Sports Medicine, 34, 221-229. https://doi.org/10.2165/00007256-200434040-00002

[12] Harris, B.A. (2005) The Influence of Endurance and Resistance Exercise on Muscle Capillarization in the Elderly: A Review. Acta Physiologica Scandinavica, 185, 8997. https://doi.org/10.1111/j.1365-201X.2005.01461.x

[13] Seene, T., Kaasik, P. and Umnova, M. (2009) Structural Rearrangements in Contractile Apparatus and Resulting Skeletal Muscle Remodelling: Effect of Exercise Training. Journal of Sports Medicine and Physical Fitness, 49, 410-423.

[14] Seene, T., Alev, K., Kaasik, P. and Pehme, A. (2007) Changes in Fast-Twitch Muscle Oxidative Capacity and Myosin Isoforms Modulation during Endurance Training. Journal of Sports Medicine and Physical Fitness, 47, 124-132.

[15] Magaudda, L., Di Mauro, D., Trimarchi, F. and Anastasi, G. (2004) Effects of Physical Exercise on Skeletal Muscle Fiber: Ultrastructural and Molecular Aspects. Basic Applied Myology, 14, 17-21.

[16] Seene, T., Kaasik, P., Alev, K., Pehme, A. and Riso, E.M. (2004) Composition and Turnover of Contractile Proteins in Volume-Overtrained Skeletal Muscle. International Journal of Sports Medicine, 25, 438-445. https://doi.org/10.1055/s-2004-820935

[17] Seene, T., Alev, K., Kaasik, P., Pehme, A. and Parring, A.M. (2005) Endurance Training: Volume-Dependent Adaptational Changes in Myosin. International Journal of Sports Medicine, 26, 815-821. https://doi.org/10.1055/s-2005-837449

[18] Folland, J.P. and Williams, A.G. (2007) The Adaptations to Strength Training: Morphological and Neurological Contributions to Increased Strength. Sports Medicine, 37, 145-168. https://doi.org/10.2165/00007256-200737020-00004

[19] Andersen, J.L. and Aagaard, P. (2000) Myosin Heavy Chain IIX Overshoot in Human Skeletal Muscle. Muscle \& Nerve, 23, 1095-1104. https://doi.org/10.1002/1097-4598(200007)23:7<1095::AID-MUS13>3.0.CO;2-O

[20] Kendall, B. and Eston, R. (2002) Exercise-Induced Muscle Damage and the Potential Protective Role of Estrogen. Sports Medicine, 32, 103-123. https://doi.org/10.2165/00007256-200232020-00003

[21] Kibler, W.B. and Chandler, T.J. (1998) Musculoskeletal and Orthopedic Considerations. In: Kreider, R.B., Fry, A.C. and O’Toole, M.L., Eds., Overtraining in Sport, Human Kinetics, Champaign, IL, 169-190.

[22] Fridén, J., Leiber, R.L. and Thornell, L.E. (1991) Subtle Indications of Muscle Damage Following Eccentric Contractions. Acta Physiologica Scandinavica, 142, 523-524. https://doi.org/10.1111/j.1748-1716.1991.tb09189.x

[23] Lehmann, M., Foster, C., Netzer, N., Lormes, W., Steinacker, J.M., Liu, Y., Opitz-Gress, A. and Gastmann, U. (1998) Physiological Responses to Short- and 
Long-Term Overtraining In Endurance Athletes. In: Kreider, R., Fry, A. and O'Toole, M., Eds., Overtraining in Sport, Human Kinetics, Champaign, IL, 19-46.

[24] Sjöström, M., Johansson, C. and Lorentzon, R. (1988) Muscle Pathomorphology in m. Quadericeps of Marathon runners. Early Signs of Strain Disease or Functional Adaptation? Acta Physiologica Scandinavica, 132, 537-541. https://doi.org/10.1111/j.1748-1716.1988.tb08362.x

[25] Umnova, M. and Seene, T. (1991) The Effect of Increased Functional Load on the Activation of Satellite Cells in the Skeletal Muscle of Adult Rats. International Journal of Sports Medicine, 12, 501-504. https://doi.org/10.1055/s-2007-1024723

[26] Seene, T. and Umnova, M. (1992) Relations between the Changes in the Turnover Rate of Contractile Proteins, Activation of Satellite Cells and Ultra-Structural Response of Neuromuscular Junctions in the Fast-Oxidative-Glucolytic Muscle Fibres in Endurance Trained Rats. Basic Applied Myology, 2, 39-46.

[27] Dauber, W., Voight, T. and Heini, A. (1999) Junctions between Subsynaptic Folds and Rough Sarcoplasmic Reticulum of Muscle Fibers. Journal of Muscle Research \& Cell Motility, 20, 697-701. https://doi.org/10.1023/A:1005521529855

[28] Dauber, W. and Meister, A. (1986) Ultrastructure of Junctional Folds of Motor End Plates in Extensor Digitorum Longus Muscle of Mice. Journal of Ultrastructure and Molecular Structure Research, 97, 158-164.

[29] Dauber, W., Voight, T., Härtel, X. and Mayer, J. (2000) The T-Tubular Network and Its Triads in the Sole Plate Sarcoplasm of the Motor End-Plate of Mammals. Journal of Muscle Research \& Cell Motility, 21, 443-449.

https://doi.org/10.1023/A:1005614917564

[30] van Wessel, T., de Haan, A., van der Laarse, W.J. and Jaspers, R.T. (2010) The Muscle Fiber Type-Fiber Size Paradox: Hypertrophy or Oxidative Metabolism? European Journal of Applied Physiology, 110, 665-694. https://doi.org/10.1007/s00421-010-1545-0

[31] Bekedam, M.A., van Beek-Harmsen, B.J., Boonstra, A., van Mechelen, W., Visser, F.C. and van der Laarse, W.J. (2003) Maximum Rate of Oxygen Consumption Related to Succinate Dehydrogenase Activity in Skeletal Muscle Fibres of Chronic Heart Failure Patients and Controls. Clinical Physiology and Functional Imaging, 23, 337-343. https://doi.org/10.1046/j.1475-0961.2003.00517.x

[32] Blomstrand, E., Rådegran, G. and Saltin, B. (1997) Maximum Rate of Oxygen Uptake by Human Skeletal Muscle in Relation to Maximal Activities of Enzymes in the Krebs Cycle. The Journal of Physiology, 501, 455-460. https://doi.org/10.1111/j.1469-7793.1997.455bn.x

[33] Hoppeler, H. and Billeter, R. (1991) Conditions for Oxygen and Substrate Transport in Muscles in Exercising Mammals. The Journal of Experimenthal Biology, 160, 263-283.

[34] Reichmann, H., Wasl, R., Simoneau, J.A. and Pette, D. (1991) Enzyme Activities of Fatty Acid Oxidation and the Respiratory Chain in Chronically Stimulated FastTwitch Muscle of the Rabbit. Pflügers Archiv: European Journal of Physiology, 418, 572-574. https://doi.org/10.1007/BF00370573

[35] Kayar, S.R. and Banchero, N. (1987) Volume Density and Distribution of Mitochondria in Myocardial Growth and Hypertrophy. Respiation Physiology, 70, 275286.

[36] Rivero, J.L., Talmadge, R.J. and Edgerton, V.R. (1999) Interrelationships of Myofibrillar ATPase Activity and Metabolic Properties of Myosin Heavy Chain-Based Fibre Types in Rat Skeletal Muscle. Histochemistry and Cell Biology, 111, 277-287. https://doi.org/10.1007/s004180050358 
[37] Bodine, S.C., Stitt, T.N., Gonzalez, M., Kline, W.O., Stover, G.L., Bauerlein, R., Zlotchenko, E., Scrimgeour, A., Lawrence, J.C., Glass, D.J. and Yancopoulos, G.D. (2001) Akt/mTOR Pathway Is a Crucial Regulator of Skeletal Muscle Hypertrophy and Can Prevent Muscle Atrophy in Vivo. Nature Cell Biology, 3, 1014-1019. https://doi.org/10.1038/ncb1101-1014

[38] Stitt, T.N., Drujan, D., Clarke, B.A., Panaro, F., Timofeyva, Y., Kline, W.O., Gonzalez, M., Yancopoulos, G.D. and Glass, D.J. (2004) The IGF-1/PI3K/Akt Pathway Prevents Expression of Muscle Atrophy-Induced Ubiquitin Ligases by Inhibiting FOXO Transcription Factors. Molecular Cell, 14, 395-403. https://doi.org/10.1016/S1097-2765(04)00211-4

[39] Lee, S.J. and McPherron, A.C. (2001) Regulation of Myostatin Activity and Muscle Growth. Proceedings of the National Academy of Sciences of the United States of America, 98, 9306-93011. https://doi.org/10.1073/pnas.151270098

[40] Zimmers, T.A., Davies, M.V., Koniaris, L.G., Haynes, P., Esquela, A.F., Tomkinson, K.N., et al. (2002) Induction of Cachexia in Mice by Systemically Administered Myostatin. Science, 296, 1486-1488. https://doi.org/10.1126/science.1069525

[41] Hickson, R.C. and Rosenkoetter, M.A. (1981) Separate Turnover of Cytochrome c and Myoglobin in the Red Types of Skeletal Muscle. The American Journal of Physiology, 241, C140-C144.

[42] Hood, D.A. (2009) Mechanisms of Exercise-Induced Mitochondrial Biogenesis in Skeletal Muscle. Applied Physiology, Nutrition, and Metabolism, 34, 465-472. https://doi.org/10.1139/H09-045

[43] Ljubicic, V., Joseph, A.M., Saleem, A., Uquccioni, G., Collu-Marchese, M., Lai, R.Y., Nquyen, L.M. and Hood, D.A. (2010) Transcriptional and Post-Transcriptional Regulation of Mitochondrial Biogenesis in Skeletal Muscle: Effects of Exercise and Aging. Biochimica et Biophysica Acta, 1800, 223-234.

[44] Stepto, N.K., Martin, D.T., Fallon, K.E. and Hawley, J.A. (2001) Metabolic Demands of Intense Aerobic Interval Training in Competitive Cyclists. Medicine and Science in Sports and Exercise, 33, 303-310. https://doi.org/10.1097/00005768-200102000-00021

[45] Yeo, W.K., Paton, C.D., Garnham, A.P., Burke, L.M., Carey, A.L. and Hawley, J.A. (2008) Skeletal Muscle Adaptation and Performance Responses to Once a Day versus Twice Every Second Day Endurance Training Regimens. Journal of Applied Physiology, 105, 1462-1470. https://doi.org/10.1152/japplphysiol.90882.2008

[46] Laursen, P.B. and Jenkins, D.G. (2002) The Scientific Basis for High-Intensity Interval Training: Optimising Training Programmes and Maximising Performance in Highly Trained Endurance Athletes. Sports Medicine, 32, 53-73. https://doi.org/10.2165/00007256-200232010-00003

[47] Iaia, F.M., Thomassen, M., Kolding, H., Gunnarsson, T., Wendell, J., Rostgaard, T., Nordsborg, N., Krustrup, P., Nybo, L., Hellsten, Y. and Bangsbo, J. (2008) Reduced Volume but Increased Training Intensity Elevates Muscle $\mathrm{Na}^{+}-\mathrm{K}^{+}$Pump $\alpha_{1}$-Subunit and NHE1 Expression as Well as Short-Term Work Capacity in Humans. American Journal of Physiology. Regulatory, Integrative and Comparative Physiology, 294, R966-R974. https://doi.org/10.1152/ajpregu.00666.2007

[48] Iaia, F.M., Hellsten, Y., Nielsen, J.J., Fernström, M., Sahlin, K. and Bangsbo, J. (2009) Four Weeks of Speed Endurance Training Reduces Energy Expenditure during Exercise and Maintains Muscle Oxidative Capacity Despite a Reduction in Training Volume. Journal of Applied Physiology, 106, 73-80. https://doi.org/10.1152/japplphysiol.90676.2008

[49] Winder, W.W. and Hardie, D.G. (1996) Inactivation of Acetyl-CoA Carboxylase 
and Activation of AMP-Activated Protein Kinase in Muscle during Exercise. The American Journal of Physiology, 270, E299-E304.

[50] Hardie, D.G. and Sakamoto, K. (2006) AMPK: A Key Sensor of Fuel and Energy Status in Skeletal Muscle. Physiology, 21, 48-60.

https://doi.org/10.1152/physiol.00044.2005

[51] McGee, S.L., Kristy, J., Mustard, D., Hardie, D.G. and Baar, K. (2008) Normal Hypertrophy Accompanied by Phosphoryation and Activation of AMP-Activated Protein Kinase $\alpha 1$ following Overload in LKB1 Knockout Mice. The Journals of Physiology, 586, 1731-1741. https://doi.org/10.1113/jphysiol.2007.143685

[52] Luquet, S., Lopez-Soriano, J., Holst, D., Fredenrich, A., Melki, J., Rassoulzadegan, M. and Grimaldi, P. (2003) Peroxisome Proliferator-Activated Receptor Delta Controls Muscle Development and Oxidative Capability. FASEB Journal, 17, 2299-2301.

[53] Wang, Y.X., Zhang, C.L., Yu, R.T., Cho, H.K., Nelson, M.C., Bayuga-Ocampo, C.R., Ham, J., Kang, H. and Evans, R.M. (2004) Regulation of Muscle Fibre Type and Running Endurance by PPAR $\delta$. PLoS Biology, 2, e294. https://doi.org/10.1371/journal.pbio.0020294

[54] Carraro, F., Stuart, C.A., Hartl, W.H., Rosenblatt, J. and Wolfe, R.R. (1990) Effect of Exercise and Recovery on Muscle Protein Synthesis in Human Subjects. The American Journal of Physiology, 259, E470-E476.

[55] Alev, K., Kaasik, P., Pehme, A., Aru, M., Parring, A.-M., Elart, A. and Seene, T. (2009) Physiological Role of Myosin Light and Heavy Chain Isoforms in Fast- and Slow-Twitch Muscles: Effect of Exercise. Biology of Sport, 26, 215-234. https://doi.org/10.5604/20831862.894654

[56] Seene, T., Kaasik, P. and Alev, K. (2011) Muscle Protein Turnover in Endurance Training: A Review. International Journal of Sports Medicine, 32, 905-911. https://doi.org/10.1055/s-0031-1284339

[57] Baldwin, K.M. and Haddad, F. (2001) Invited Review: Effect of Different Activity and Inactivity Paradigms on Myosin Heavy Chain Gene Expression in Studied Muscle. Journal of Applied Physiology, 90, 345-357.

[58] Hayashibara, T. and Miyanishi, T. (1994) Binding of the Amino-Terminal Region of Myosin Alkali 1 Light Chain to Actin and Its Effect on Actin-Myosin Interaction. Biochemistry, 33, 12821-12827. https://doi.org/10.1021/bi00209a013

[59] Green, H.J., Reichmann, H. and Pette, D. (1983) Fibre Type Specific Transformations in the Enzyme Activity Pattern of Rat Vastus Lateralis Muscle by Prolonged Endurance Training. Pflügers Archiv. European Journal of Physiology, 399, 216222. https://doi.org/10.1007/BF00656718

[60] van der Vusse, G.J., Glatz, J.F., Stam, H.C. and Reneman, R.S. (1992) Fatty Acid Homeostasis in the Normoxic and Ischemic Heart. Physiological Reviews, 72, 881940.

[61] Matsakas, A., Macharia, R., Otto, A., Elashry, M.I., Mouisel, E., Romanello, V., Sartori, R., Amthor, H., Sandri, M., Narkar, V. and Patel, K. (2012) Exercise Training Attenuates the Hypermuscular Phenotype and Restores Skeletalmuscle function in the myostatin null mouse. Experimental Physiology, 97, 125-140. https://doi.org/10.1113/expphysiol.2011.063008

[62] Pierce, G.N., Sekhon, P.S., Meng, H.P. and Maddaford, T.G. (1989) Effects of Chronic Swimming Training on Cardiac Sarcolemmal Function and Composition. Journal of Applied Physiology, 66, 1715-1721.

[63] Jin, H., Yang, R., Li, W., Lu, H., Ryan, A.M., Ogasawara, A.K., Van Peborgh, J. and Paoni, N.F. (2000) Effects of Exercise on Cardiac Function, Gene Expression and Apoptosis in Rats. American Journal of Physiology. Heart and Circulatory Physio- 
logy, 279, 2994-3002.

[64] Wisloff, U., Loennechen, J.P., Falck, G., Beisvag, V., Currie, S., Smith, G. and Ellingsen, O. (2001) Increased Conractility and Calcium Sensitivity in Cardiac Myocytes Isolated from Endurance Trained Rats. Cardiovascular Research, 50, 495 508. https://doi.org/10.1016/S0008-6363(01)00210-3

[65] Diffee, G.M., Seversen, E.A., Stein, T.D. and Johnson, J.A. (2003) Microarray Expression Analysis of Effects of Exercise Training: Increase in Atrial MLC-1 in Rat Ventricles. American Journal of Physiology. Heart and Circulatory Physiology, 284, H830-H837. https://doi.org/10.1152/ajpheart.00761.2002

[66] Tate, C.A., Helgason, T., Hyek, M.F., McBride, R.P., Chen, M., Richardson, M.A. and Taffet, G.E. (1996) SERCA2a and Mitochondrial Cytochrome Oxidase Are Increased in Hearts of Exercise-Trained Old Rats. American Journal of Physiology, 271, 68-72.

[67] Nuhr, M., Crevenna, R., Gohlsch, B., Bittner, C., Pleiner, J., Wiesinger, G., FialkaMoser, V., Quittan, M. and Pette, D. (2003) Functional and Biochemical Properties of Chronically Stimulated Human Skeletal Muscle. European Journal of Applied Physiology, 89, 202-208. https://doi.org/10.1007/s00421-003-0792-8

[68] Holloszy, J.O. (1967) Biochemical Adaptations in Muscle. Effects of Exercise on Mitochondrial Oxygen Uptake and Respiratory Enzyme Activity in Skeletal Muscle. The Journal of Biological Chemistry, 242, 2278-2282.

[69] Silva, L.A., Pinho, C.A., Scarabelot, K.S., Fraga, D.B., Volpato, A.M., Boeck, C.R., De Souza, C.T., Streck, E.L. and Pinho, R.A. (2009) Physical Exercise Increases Mitochondrial Function and Reduces Oxidative Damage in Skeletal Muscle. European Journal of Applied Physiology, 105, 861-867. https://doi.org/10.1007/s00421-008-0971-8

[70] Spina, R.J., Chi, M.M., Hopkins, M.G., Nemeth, P.M., Lowry, O.H. and Holloszy, J.O. (1996) Mitochondrial Enzymes Increase in Muscle in Response to 7 - 10 Days of Cycle Exercise. Journal of Applied Physiology, 80, 2250-2254.

[71] Terblanche, S.E., Gohil, K., Packer, L., Henderson, S. and Brooks, G.A. (2001) The Effects of Endurance Training and Exhaustive Exercise on Mitochondrial Enzymes in Tissues of the Rat (Rattus norvegicus). Comparative Biochemistry and Physiology. Part A, Molecular \& Integrative Physiology, 128, 889-896.

[72] Bozner, A. and Meessen, H. (1969) The Ultrastructure of the Myocardium of the Rat after Single and Repeated Swim Exercises. Virchows Archiv. B: Cell Pathology, 3, 248-269.

[73] Anversa, P., Beghi, C., Levicky, V., McDonald, S.L. and Kikkawa, Y. (1982) Morphometry of Right Ventricular Hypertrophy Induced by Strenuous Exercise in Rat. The American Journal of Physiology, 243, 856-861.

[74] Kayar, S.R., Conley, K.E., Claassen, H. and Hoppeler, H. (1986) Capillarity and Mitochondrial Distribution in Rat Myocardium Following Exercise Training. The Journal of Experimental Biology, 120, 189-199.

[75] Paniagua, R., Vázques, J.J. and López-Moratalla, N. (1977) Effects of Physical Training on Rat Myocardium. An Enzymatic and Ultrastructural Morphometric Study. Revista Española de Fisiologia, 33, 273-281.

[76] Noble, E.G., Moraska, A., Mazzeo, R.S., Roth, D.A., Olsson, M.C., Moore, R.L. and Fleshner, M. (1999) Differential Expression of Stress Proteins in Rat Myocardium after Free Wheel or Treadmill Run Training. Journal of Applied Physiology, 86, 1696-1701.

[77] Gleyzer, N., Vercauteren, K. and Scarpulla, R.C. (2005) Control of Mitochondrial Transcription Specificity Factors (TFB1M and TFB2M) by Nuclear Respiratory 
Factors (NRF-1 and NFR-2) and PGC-1 Family Coactivators. Molecular and Cell Biology, 25, 1354-1366. https://doi.org/10.1128/MCB.25.4.1354-1366.2005

[78] Scheller, K. and Sekeris, C.E. (2003) The Effects of Steroid Hormones on the Transcription of Genes Encoding Enzymes of Oxidative Phosphorylation. Experimental Physiology, 88, 129-140. https://doi.org/10.1113/eph8802507

[79] Akimoto, T., Pohnert, S.C., Li, P., Zhang, M., Gumbs, C., Rosenberg, P.B., Williams, R.S. and Yan, Z. (2005) Exercise Stimulates PGC-1 $\alpha$ Transcription in Skeletal Muscle through Activation of the p38 MAPK Pathway. The Journal of Biological Chemistry, 280, 19587-19593. https://doi.org/10.1074/jbc.M408862200

[80] Fan, M., Rhee, J., St-Pierre, J., Handschin, C., Puigserver, P., Lin, J., Jäeger, S., Erdjument-Bromage, H., Tempst, P. and Spiegelman, B.M. (2004) Suppression of Mitochondrial Respiration through Recruitment of p160 myb Binding Protein to PGC-1 $\alpha$ : Modulation by p38 MAPK. Genes \& Development, 18, 278-289. https://doi.org/10.1101/gad.1152204

[81] Puigserver, P., Rhee, J., Lin, J.Wu, Z., Yoon, J.C., Zhang, C.Y., Krauss, S., Mootha, V.K., Lowell, B.B. and Spiegelman, B.M. (2001) Cytokine Stimulation of Enenrgy Expenditure through p38 MAP kInase Activation of PPAR $\gamma$ Coactivator-1. Molecular Cell, 8, 971-982. https://doi.org/10.1016/S1097-2765(01)00390-2

[82] Narkar, V.A., Downes, M., Yu, R.T., Embler, E., Wang, Y.X., Banayo, E., Mihaylova, M.M., Nelson, M.C., Zou, Y., Juguilon, H., Kang, H., Shaw, R.J. and Evans, R.M. (2008) AMPK and PPAR $\delta$ Agonists Are Exercise Mimetics. Cell, 134, 405-415. https://doi.org/10.1016/j.cell.2008.06.051

[83] Menzies, K.J. and Hood, D.A. (2012) The Role of SirT1 in Muscle Mitochondrial Turnover. Mitochondrion, 12, 5-13.

[84] Amat, R., Planavila, A., Chen, S.L., Iglesias, R., Giralt, M. and Villarroya, F. (2009) SIRT1 Controls the Transcription of the Peroxisome Proliferator-Activated Receptor- $\gamma$ Co-activator-1 $\alpha$ (PGC-1 $\alpha$ ) Gene in Skeletal Muscle through the PGC-1 $\alpha$ Autoregulatory Loop and Interaction with MyoD. The Journal of Biological Chemistry, 284, 21872-21880. https://doi.org/10.1074/jbc.M109.022749

[85] Dumke, C.L., Davis, J.M., Murphy, E.A., Nieman, D.C., Carmichael, M.D., Quindry, J.C., Travis Triplett, N., Utter, A.C., Gross Gowin, S.J., Henson, D.A., McAnulty, S.R. and McAnulty, L.S. (2009) Successive Bouts of Cycling Stimulates Genes Associated with Mitocondrial Biogenesis. European Journal of Applied Physiology, 107, 419-427. https://doi.org/10.1007/s00421-009-1143-1

[86] Pillai, V.B., Sundaresan, N.R., Jeevanandam, V. and Gupta, M.P. (2010) Mitochondrial SIRT3 and Heart Disease. Cardiovascular Research, 88, 250-256. https://doi.org/10.1093/cvr/cvq250

[87] Gurd, B.J., Holloway, G.P., Yoshida, Y. and Bonen, A. (2011) In Mammalian Muscle, SIRT3 Is Present in Mitochondria and Not in the Nucleus; and SIRT3 Is Upregulated by Chronic Muscle Contraction in an Adenosine MonophosphateActivated Protein Kinase-Independent Manner. Metabolism: Clinical and Experimental, 61, 733-741.

[88] Wu, Z., Huang, X., Feng, Y., Handschin, C., Feng, Y., Gullicksen, P.S., Bare, O., Labow, M., Spiegelman, B. and Stevenson, S.C. (2006) Transducer of Regulated CREB-Binding Proteins (TORCs) Induce PGC-1 $\alpha$ Transcription and Mitochondrial Biogenesis in Muscle Cells. Proceedings of National Academy of Sciences of the United States of America, 103, 14379-14384. https://doi.org/10.1073/pnas.0606714103

[89] Matoba, S., Kang, J.G., Patino, W.D., Wragg, A., Boehm, M., Gavrilova, O., Hurley, P.J., Bunz, F. and Hwang, P.M. (2006) p53 Regulates Mitochondrial Respiration. 
Scince, 312, 1650-1653. https://doi.org/10.1126/science.1126863

[90] Achanta, G., Sasaki, R., Feng, L., Carew, J.S., Lu, W., Pelicano, H., Keating, M.J. and Huang, P. (2005) Novel Role of p53 in Maintaining Mitochondrial Genetic Stability through Interaction with DNA Pol Gamma. The EMBO Journal, 24, 3482-3492. https://doi.org/10.1038/sj.emboj.7600819

[91] Park, J.-Y., Wang, P.-Y., Matsumoto, T., Sung, H.J., Ma, W., Choi, J.W., Anderson, S.A., Leary, S.C., Balaban, R.S., Kang, J.G. and Hwang, P.M. (2009) p53 Improves Aerobic Exercise Capacity and Augments Skeletal Muscle Mitochondrial DNA Content. Circulation Research, 105, 705-712. https://doi.org/10.1161/CIRCRESAHA.109.205310

[92] Saleem, A., Adhietty, P.J. and Hood, D.A. (2009) Role of p53 in Mitochondrial Biogenesis and Apoptosis in Skeletal Muscles. Physiological Genomics, 37, 58-66. https://doi.org/10.1152/physiolgenomics.90346.2008

[93] Rodriguez.-Bies, E., Santa-Cruz, S., Fontan-Lozano, A., Amaro, J.P., Berral de la Rosa, F.J., Carrion, A.M., Navas, P. and Lopez-Lluch, G. (2010) Muscle Physiology Changes Induced by Every Other Day Feeding and Endurance in Mice: Effects on Physical Performance. PLoS ONE, 5, e13900.

https://doi.org/10.1371/journal.pone.0013900

\section{Scientific Research Publishing}

Submit or recommend next manuscript to SCIRP and we will provide best service for you:

Accepting pre-submission inquiries through Email, Facebook, LinkedIn, Twitter, etc. A wide selection of journals (inclusive of 9 subjects, more than 200 journals)

Providing 24-hour high-quality service

User-friendly online submission system

Fair and swift peer-review system

Efficient typesetting and proofreading procedure

Display of the result of downloads and visits, as well as the number of cited articles

Maximum dissemination of your research work

Submit your manuscript at: http://papersubmission.scirp.org/

Or contact health@scirp.org 